\title{
GEOCRONOLOGIA Pb-Pb e Rb-Sr DE GRANITÓIDES ARQUEANOS DA REGIÃO DE REDENÇÃO - SUL DO PARÁ
}

\author{
ALAYDE ALFAIA BARBOSA \& JEAN-MICHEL LAFON
}

\begin{abstract}
Pb}-\mathrm{Pb}$ AND Rb-Sr GEOCHRONOLOGY OF ARCHEAN GRANITÓIDES IN REDENCC̃O REGION - SOUTHERN PARÁ New Rb-Sr and Pb-Pb geochronological results on whole rocks and minerals are presented for Archean granitoids from the Redenção region, south of the Carajás Metallogenic Province (southeastern Pará)

In the northern part of the region, a tonalitic gneiss provided conventional biotite ages of $1849 \pm 48 \mathrm{Ma}(1 \sigma)$ and 2143 $\pm 50 \mathrm{Ma}(\mathrm{la})$ and a $\mathrm{Pb}-\mathrm{Pb}$ whole rock age of $2872 \pm 25 \mathrm{Ma}(1 \sigma)$. A monzogranitic body furnished conventional and isochronic $\mathrm{Rb}-\mathrm{Sr}$ ages of $2055 \pm 58 \mathrm{Ma}(\mathrm{la})$ and $2541 \pm 83 \mathrm{Ma}(\mathrm{l} \sigma)$ respectively, and a $\mathrm{Pb}-\mathrm{Pb}$ whole rock age of 2894 $\pm 19 \mathrm{Ma}(1 \sigma)$

In the southern part of the region (south of the Serra of Inajá), an undeformed monzogranitic body provided conventional $\mathrm{Rb}-\mathrm{Sr}$ biotite ages of $2041 \pm 92 \mathrm{Ma}(\mathrm{l} \sigma)$ and $2175 \pm 62 \mathrm{Ma}(\mathrm{l} \sigma)$. A Pb-Pb whole rock age of $2797 \pm 28$ $\mathrm{Ma}$ (la) has been obtained for the same body.

$\mathrm{The} \mathrm{Pb}-\mathrm{Pb}$ ages point out to the existence of at least two magmatic events in the Redenção region dated at $2.89-2.87$ $\mathrm{Ga}$ and at $2.80 \mathrm{Ga}$, in the northern and southern parts of the region, respectively. The ages of 2.89 and $2.87 \mathrm{Ga}$ in the northern area suggest the existence of granitoids similar to those in the Rio Maria region, associated to the greenstones belts. On the other hand, no evidences of magmatic events of $2.97 \mathrm{Ga}$ or older $(3.0 \mathrm{Ga})$, as those documented in the Rio Maria region, have been recognized in the Redenção region.

The $\mathrm{Rb}-\mathrm{Sr}$ ages are considered as a consequence of disturbance of the $\mathrm{Rb}$-Sr system due to a Late Archean thermo-tectonic event and to a Paleoproterozoic thermal event, associated to anorogenic granitic intrusions, as it had been proposed in other regions of the Carajás Metallogenic Province.
\end{abstract}

Keywords: Geochronology, Archean granitoids, Redenção region, Eastern Amazonia.

RESUMO Novos dados geocronológicos $\mathrm{Rb}-\mathrm{Sr}$ e $\mathrm{Pb}-\mathrm{Pb}$ em rocha total e minerais foram obtidos para granitóides arqueanos da região de Redenção, localizada no sul da Província Mineral de Carajás. Na porção norte da região de Redenção, um ortognaisse tonalftico apresentou idades convencionais Rb-Sr em biotita de $1849 \pm 48$ Ma

(l a) e $2143 \pm 50 \mathrm{Ma}(1 \sigma)$ e uma idade $\mathrm{Pb}-\mathrm{Pb}$ em rocha total de $2872 \pm 25 \mathrm{Ma}(1 \sigma)$. Um corpo monzogranítico forneceu idades $\mathrm{Rb}-\mathrm{Sr}$ convencionais em biotita e isocrônica de $2055 \pm 58 \mathrm{Ma}(1 \sigma)$ e $2541 \pm 83 \mathrm{Ma}(1 \sigma)$, respectivamente, bem como uma idade $\mathrm{Pb}-\mathrm{Pb}$ em rocha total de $2894 \pm 19 \mathrm{Ma}(1 \sigma)$. A sul da Serra do Inajá, um outro corpo monzogranítico forneceu idades $\mathrm{Rb}$-Sr convencionais em biotita de $2041 \pm 92 \mathrm{Ma}$ (Ia) e $2175 \pm 62 \mathrm{Ma}$ (Ia), e Pb-Pb em rocha total de $2797 \pm 28 \mathrm{Ma}(1 \sigma)$. Os resultados $\mathrm{Pb}$ - $\mathrm{Pb}$ evidenciam a ocorrência de pelo menos dois eventos magmáticos arqueanos distintos na região de Redenção com idades de 2,87 - 2,89 Ga, na porção norte, e 2,80 Ga, na porção sul. As idades de 2,87-2,89 Ga revelam a existência de granitóides com idades similares às daqueles encontrados mais a norte na região de Rio Maria em associação com os greenstone belts. Por outro lado, ao contrário do que ocorre na região de Rio Maria, idades de 2,97 Ga ou mais antigas não foram evidenciadas até o momento. As idades Rb-Sr, a exemplo do que ocorre em toda a Província Mineral de Carajás, refletem a reabertura do sistema Rb-Sr provocada pelo evento tectono-metamórfico do final do Arqueano e pelo evento térmico do Paleoproterozóico, associado a intrusão de granitos anorogênicos.

Palavras-chaves: geocronologia, granitóides, região de Redenção, Amazônia Oriental, Arqueano.

INTRODUÇÃO A Província Mineral de Carajás (PMC) destaca-se como a região que possui o maior acervo de dados geológicos e geocronológicos da Amazônia Oriental. No entanto, algumas áreas, como a região de Redenção, na porção mais meridional da PMC, são ainda carentes de estudos geológicos mais aprofundados, prejudicando a elaboração do quadro geotectônico da Província.

A região de Redenção foi investigada inicialmente pelo Projeto Radambrasil (Silva et al 1974 e Cunha et al. 1981) onde foi reunida grande parte das informações geocronológicas, petrológicas e geoquímicas disponíveis para as rochas dessa área. Trabalhos realizados no âmbito do Programa de Levantamento Geológico Básico pela Companhia de Pesquisa e Recursos Minerais CPRM/SUREG - Belém (Relatório interno, CPRM) levaram à individualização das principais unidades geológicas arqueanas anteriormente agrupadas no Complexo Xingu, à elaboração de um quadro estratigráfíco e geotectônico e estabelecendo correlações estruturais e estratigráficas com os terrenos granito-greenstones da região de Rio Maria (Araújo \& Costa 1994, Costa et al. 1995).

Poucas foram as unidades datadas na região de Redenção, e estas o foram empregando os métodos Rb-Sr e K-Ar. Esses métodos permitiram caracterizar as principais épocas da evolução da região, separando as unidades arqueanas das proterozóicas. Contudo, estes métodos são muito sensíveis aos efeitos de eventos geológicos superpostos, mesmo os de baixa intensidade, limitando a sua aplicação e a interpretação dos seus resultados.

A carência de dados geocronológicos na região de Redenção prejudicou o estabelecimento de cronocorrelações com as outras regiões da PMC, deixando em aberto questões tais como a existência de uma crosta continental mais antiga do que 3,0 Ga, a definição de um embasamento regional para os greenstone belts, as idades dos principais eventos termotectônicos que ocorreram na região e as relações temporais entre os eventos magmáticos e tectônicos.

Os primeiros resultados obtidos pelo método $\mathrm{Pb}-\mathrm{Pb}$ em rocha total de unidades magmáticas da $\mathrm{PMC}$, forneceram valiosas informações sobre as idades de sua formação (Rodrigues 1992, Lafon et al. 1994, 1995). Para este trabalho empregou-se o método $\mathrm{Pb}-\mathrm{Pb}$ em conjunto com o método $\mathrm{Rb}-\mathrm{Sr}$ em rocha total e minerais, aplicados às unidades magmáticas arqueanas que predominam na região de Redenção. Datações $\mathrm{Pb}-\mathrm{Pb}$ em rocha total foram realizadas nas unidades conhecidas como Ortognaisse Arco Verde e monzogranitos tipo Mata Surrão (Araújo \& Costa 1994), na tentativa de evidenciar se as mesmas representam produtos de eventos magmáticos distintos, como na região de Rio Maria onde essas 
unidades foram inicialmente reconhecidas. As idades $\mathrm{Rb}-\mathrm{Sr}$ em rocha total e minerais foram determinadas para evidenciar os efeitos dos eventos termo-tectônicos do final do Arqueano e do Proterozóico sobre as rochas da região de Redenção. Os dados apresentados trazem novas referências cronológicas para a evolução geotectônica da região e colaboram com as tentativas de integração que vêm sendo realizadas com as regiões adjacentes à $\mathrm{PMC}$.

CONTEXTO GEOLÓGICO REGIONAL A PMC localiza-se na porção SE do Estado do Pará, constitui o limite sul-oriental do Cráton Amazônico (Almeida 1967), e está limitada a leste pelo Cinturão Araguaia. Hirata et al. (1982), Araújo et al. (1988), DOCEGEO (1988), Huhn et al. (1988) e Costa et al. (1990) apresentaram propostas de arranjo litoestratigráfico para a PMC, estabelecendo a existência de um núcleo de terrenos granito-greenstones preservados na porção sul (região de Rio Maria - Serra dos Gradaús) e de um cinturão de cisalhamento em toda a porção centro norte (Cinturão de Cisalhamento Itacaiúnas). Araújo et al. (1994), Araújo \& Costa (1994) e Costa et al (1995) integraram a região de Redenção, localizada a sul da região de Rio Maria, em um modelo de evolução estrutural para a PMC, caracterizando os eventos termo-tectônicos que conduziram à edificação do segmento crustal da região sudeste do Estado do Pará. O principal evento reconhecido, do final do Arqueano, subdividiu a PMC em três compartimentos tectônicos, denominados, de norte para sul, de Cinturão de Cisalhamento Itacaiúnas, Terreno Granito-Greenstones de Rio Maria e Cinturão Pau d'Arco (Fig. 1). O desenvolvimento desses compartimentos é interpretado por meio de um evento termo-tectônico que iniciou com movimentos tangenciais de sul para norte, e

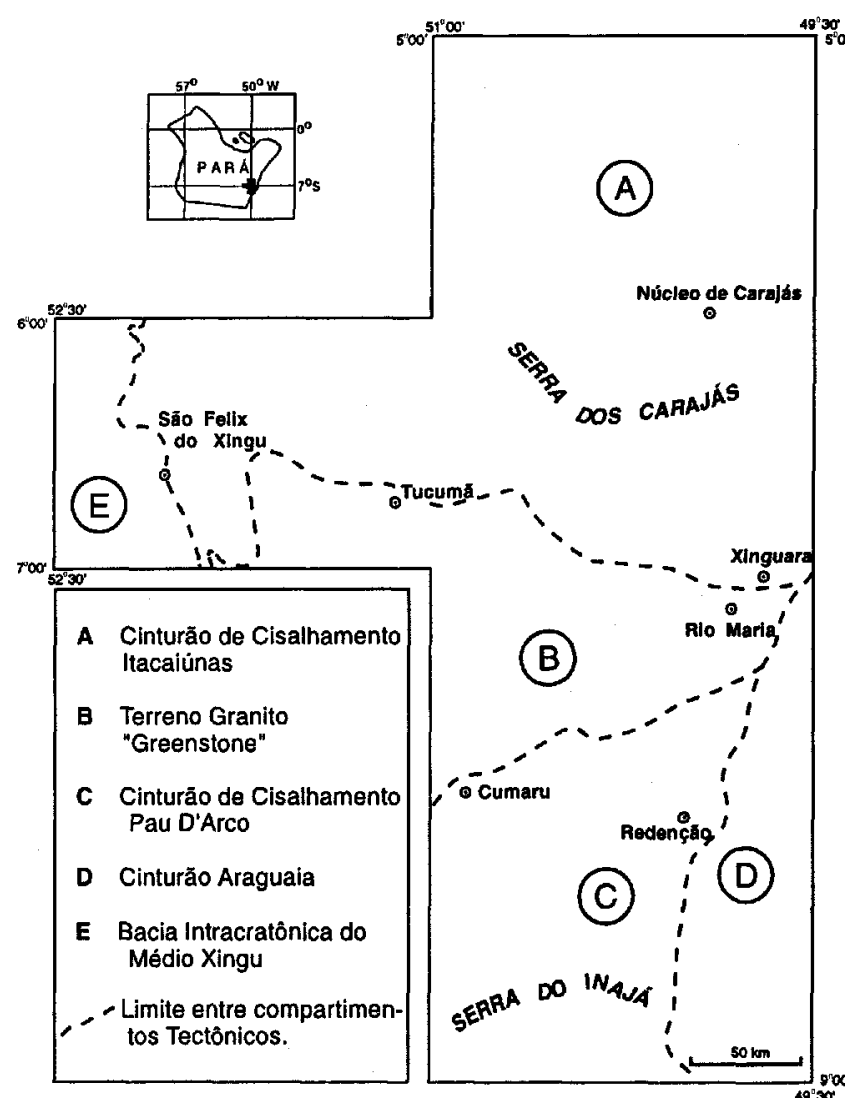

Figura 1 - Arcabouço estrutural da Província Mineral de Carajás (seg. Costa et al. 1995).

Figure 1 - Structural arrangement of the Mineral Province of Carajás (Costa et al. 1995). evoluiu para movimentos essencialmente direcionais. A evolução anterior a esse evento e, em particular, as condições de formação da crosta arqueana da PMC, ainda é uma incógnita (Macambira \& Lafon 1995).

A região de Redenção, situada logo a sul dos terrenos granito-greenstone de Rio Maria, estende-se pelo menos até a Serra do Inajá onde seqüências de greenstone também foram identificadas (Fig. 1). As unidades litológicas contêm uma foliação milonítica orientada segundo $\mathrm{E}-\mathrm{W}$ e com mergulho acentuado para $\mathrm{N}$ ou $\mathrm{S}$, e uma lineação de estiramento subhorizontal (Araújo et al. 1994). A ocorrência de granitóides em faixas e lentes em meio aos gnaisses define um bandamento orientado preferencialmente na direção E-W, tratandose de uma geometria resultante de forte deformação por milonitização, cuja movimentação se concentra nos contatos e gera as principais zonas de cisalhamento (Costa et al. 1995). Essas feições levaram Araújo et al. (1994) e Costa et al. (1995) a definir um cinturão de cisalhamento na região. Por outro lado Althoff et al. (1991, 1995), a partir de dados petrográfícos e estruturais dos granitóides da região de Marajoara, consideram que a mesma é um prolongamento do bloco crustal arqueano de Rio Maria e descartam a hipótese de ocorrer, na área, um cinturão de cisalhamento no limite daquele bloco.

Durante o Proterozóico, toda a PMC foi afetada por movimentos extensionais que geraram falhas normais e de transferência orientadas respectivamente segundo NE-SE e NE-SW. Coberturas vulcânicas e sedimentares e granitos anorogênicos estão intimamente relacionados a esse evento termo-tectônico (Costa et al. 1990, 1995).

Em um primeiro esboço estratigráfico para a região de Redenção, o Complexo Xingu, cujas litologias foram descritas como granitos, granodioritos, gnaisses, migmatitos, anatexitos, anfibolitos e charnoquitos, era considerado como o embasamento regional arqueano constituindo, junto com as seqüências tipo greenstone belt do Grupo Serra do Inajá, as unidades mais antigas da região (Silva et al. 1974, Cunha et al 1981, Ianhez et al. 1980, 1982, Bezerra et al 1982).

Cunha et al (1981) obtiveram idades $\mathrm{Rb}-\mathrm{Sr}$ em rocha total de 2,70 Ga e de 2,0 Ga em rochas do Complexo Xingu na região de Redenção, interpretadas respectivamente como a época de formação dessas rochas e do seu rejuvenescimento isotópico durante o Ciclo Transamazônico. Rochas do Complexo Xingu também foram datadas por Bezerra et al (1982) pelo método $\mathrm{K}-\mathrm{Ar}$ em rocha total e minerais, mostrando idades de 2,2 a 1,7Ga.

Entre as cidades de Redenção e Marajoara (Fig. 2), Althoff et al (1995) dividiram o Complexo Xingu em três grupos de granitóides arqueanos, quais sejam, o Tonalito Arco Verde, de afinidade trondhjemítica, o Granito Guarantã e o Granodiorito Rio Maria, de afinidade cálcialcalina. Para esses autores, o Tonalito Arco Verde $(2957+257-21 \mathrm{Ma}$ U-Pb em zircão, Macambira \& Lancelot, no prelo) é a unidade mais antiga, enquanto o Granodiorito Rio Maria, correlacionado ao corpo homônimo da região de Rio Maria, tem idade U-Pb em zircão de 2874 +97-10 Ma (Macambira \& Lancelot 1991, no prelo) e $2872 \pm 5$ Ma (Pimentel \& Machado 1994). Não existem dados geocronológicos do Granito Guarantã, mas os autores o consideram como gerado logo após o Tonalito Arco Verde tendo, portanto, idade próxima desse último.

Araújo et al (1 994) e Costa et al (1 995) dividiram também o Complexo Xingu, na região de Redenção (Fig. 2), em três grupos de granitóides, similares aos definidos por Althoff et al (1995). Entretanto, interpretam o Tonalito Arco Verde como um ortognaisse tonalítico migmatizado e relacionam os monzogranitos da região de Redenção ao Granito Mata Surrão da de Rio Maria datado em $2875 \pm 20 \mathrm{Ma}(\mathrm{Pb}-\mathrm{Pb}$ em rocha total; Lafon et al 1994), e portanto contemporâneo ao Granodiorito Rio Maria. 
O Grupo Serra do Inajá, que ocorre no sul da região de Redenção (Fig. 2), caracteriza-se por uma diversificada seqüência litológica vulcano-sedimentar, constituída, da base para o topo, por metaultramáficas, metamáficas, metavulcânicas félsicas e rochas metassedimentares metamorfizadas na fácies xisto verde a epídoto-anfibolito (Silva et al 1974, lanhez et al. 1980). DOCEGEO (1988) e Araújo \& Costa (1994) caracterizam definitivamente esse grupo como uma seqüência do tipo greenstone belt. Não há dados geocronológicos do Grupo Serra do Inajá, mas lanhez et al. (1980) sugerem que sua formação ocorreu entre 3,0 e 2,6.

De acordo com Silva et al. (1974), Cunha et al. (1981) e Costa et al. (1991), as rochas relacionadas à evolução das estruturas extensionais que caracterizam o Proterozóico na PMC, compreendem complexos máfíco-ultramáfícos, associações plutônicas e vulcânicas félsicas (Supergrupo Uatumã), rochas sedimentares (Formação Gorotire e Cubencranquém) e plutônicas (Suítes Tarumã e Redenção). Dessas unidades, apenas a suíte Redenção e a Formação Gorotire estão representadas na região de Redenção.

A Formação Gorotire consiste de um pacote de arenitos com horizontes subordinados de granulometria mais fina e conglomerados, sobreposto discordantemente ao Supergrupo Uatumã e sotoposto à Formação Cubencranquém.

A Suíte Intrusiva Redenção engloba corpos graníticos relacionados ao evento plutônico ácido considerado até o momento como o mais jovem evento da Plataforma Amazônica (Bezerra et al. 1982). Cunha et al. (1 981) obtiveram uma idade
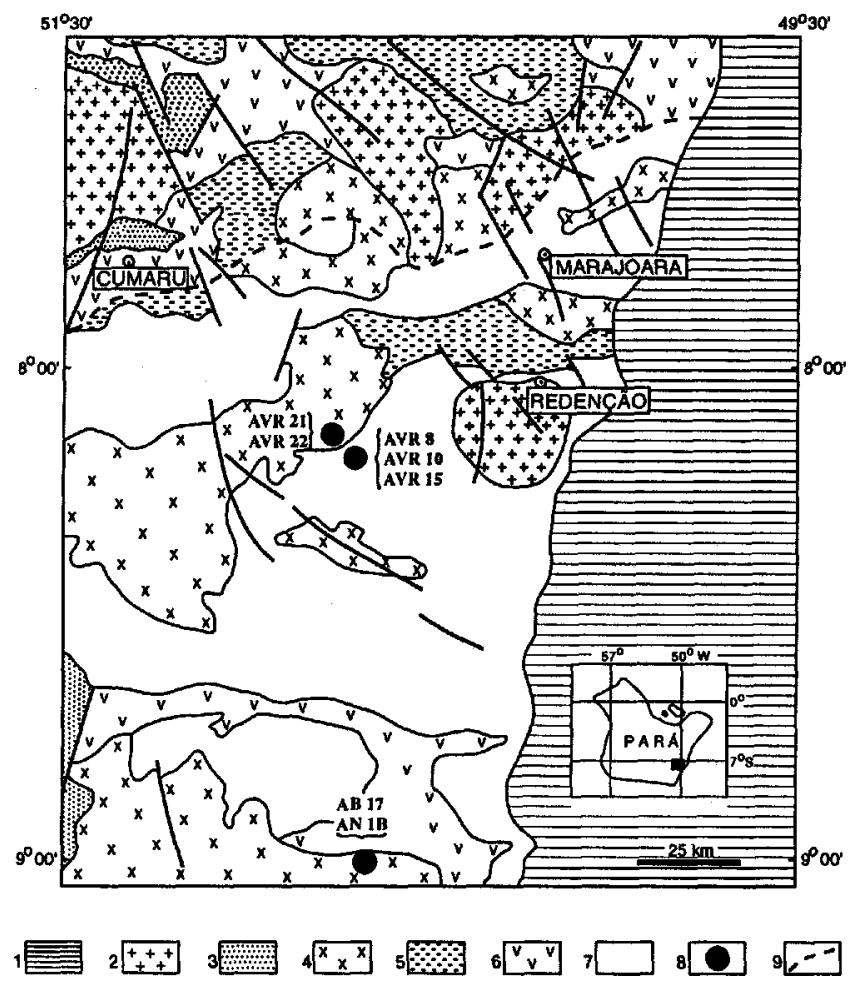

Figura 2 - Mapa geológico simplificado da região de Redenção, l- Cinturão Araguaia; 2-Granitos anorogênicos paleoproterozóicos; 3-Coberturas sedimentares; 4-monzogranitos tipo Mata Surrão; 5-Granodiorito Rio Maria; 6-Sequências greenstones; 7-Ortognaisse Arco Verde. (Fonte: Costa et al. 1995, modificado).

Figure 2 - Simplified geologic map of the Redenção region, 1-Araguaia Belt; 2-Paleoproterozoic anorogenic granites; 3-Sedimentary cover; 4-Archean monzogranites; 5-Rio Maria granodiorite; 6-Greenstones sequences; 7-Arco Verde orthogneiss. (Source: Costa e tal. 1995, modified). convencional $\mathrm{Rb}-\mathrm{Sr}$ de $685 \pm 30 \mathrm{Ma}$, enquanto Tassinari et al. (1984) apresentam, para o Granito Redenção, uma idade isocrônica $\mathrm{Rb}-\mathrm{Sr}$ de $1350 \pm 80 \mathrm{Ma}$, interpretada como a de cristalização do mesmo. Finalmente, Barbosa et al. (1995) obtiveram uma idade isocrônica $\mathrm{Pb}-\mathrm{Pb}$ em rocha total de 1870 $\pm 68 \mathrm{Ma}$ interpretada como a de cristalização do Granito Redenção. Esse resultado é similar às idades U-Pb em zircão e $\mathrm{Pb}-\mathrm{Pb}$ em rocha total de 1,87 -1,89 Ga dos demais granitos anorogênicos da PMC, implicando em uma revisão da cronologia dos eventos magmáticos e sedimentares ocorridos durante o Proterozóico na região de Redenção, estabelecida a partir de dados $\mathrm{Rb}-\mathrm{Sr}$.

DESCRIÇÃO DAS UNIDADES ESTUDADAS Neste trabalho será dado ênfase ao Ortognaisse Arco Verde e aos monzogranitos tipo Mata Surrão, levando-se em consideração, a priori, a divisão litoestratigráfica proposta por Costa et al. (1995), já que as rochas investigadas não pertencem à área estudada por Althoff et al. (1995).

Ortognaisse Arco Verde As amostras desta unidade foram coletadas em três pontos (AVR10, AVR08 e AVR15), em afloramentos sob a forma de extensos lajeados expostos nos ramais da estrada situada a oeste da Cidade de Redenção (Fig. 2).

O Ortognaisse Arco Verde é acinzentado, de granulação média e contem encraves centimétricos de anfibolito. Em geral, são gnaisses com um bandamento composicional dado pela alternância de leitos contínuos, quartzo-feldspáticos e máficos, constituídos principalmente por biotita, associado a uma foliação milonítica de direção geral NE-SW subvertical. São comuns mobilizados quartzo-feldspáticos e quartzosos, os quais ocorrem como níveis concordantes ou discordantes à foliação. Localmente, o gnaisse mostra porções isotrópicas nas quais foram coletadas as amostras para determinações geocronológicas.

Ao microscópio, as amostras estudadas, provenientes das porções isotrópicas, apresentam uma textura granoblástica com uma sutil orientação dos grãos maiores de plagioclásio e da biotita. Os minerais essenciais consistem de plagioclásio, feldspato potássico (microclina pertítica) e quartzo, com proporções médias respectivas de 41\% (30-51\%), 9\% (1-19\%) e $29 \%$ (16-37\%), definindo uma composição tonalítica a granodiorítica, segundo o critério de Streckeisen (1976). A hornblenda e a biotita são varietais. Os acessórios compreendem alanita, apatita, opacos e zircão e os secundários são epídoto (alteração do plagioclásio e da biotita), clorita (alteração do anfibólio), sericita e argilo-minerais (alteração do plagioclásio e feldspato potássico). A biotita contem, em geral, inclusões de epídoto, opacos, quartzo e apatita granular.

Monzogranitos tipo Mata Surrão Na região de Redenção foram identificadas duas áreas de ocorrência de monzogranitos, correlacionados por Araújo \& Costa (1994) ao Granito Mata Surrão da região de Rio Maria (Fig. 2). Uma localiza-se a oeste da cidade de Redenção e outra é um corpo que aflora a sul da Serra do Inajá. De acordo com dados inéditos da CPRM, esses corpos apresentam características petrográficas e geoquímicas semelhantes.

O Granito Mata Surrão foi definido por Duarte et al. (1991) na região de Rio Maria como um granito geralmente isótropo encaixado no Tonalito Arco Verde. Esse corpo apresenta idades $\mathrm{Pb}-\mathrm{Pb}$ em rocha total de $2875 \pm 20 \mathrm{Ma}$ (Lafon et al. 1994) e Rb-Sr de $2541 \pm 74 \mathrm{Ma}$ (Duarte et al. 1991) interpretadas, respectivamente, como a de cristalização e a de rejuvenescimento isotópico.

As amostras de monzogranito tipo Mata Surrão foram coletadas em dois pontos (AVR21 e AVR22) na porção norte da área, e dois na porção sul (ANO l e AB17B), em afloramen- 
tos sob a forma de lajeados e blocos métricos, em ramais da rodovia PA-150. As amostras da porção sul provém de uma área próxima à Serra do Inajá, onde Cunha et al. (1981) identificaram corpos da Suíte Intrusiva Proterozóica Rio Dourado. Contudo Araújo \& Costa (1994) e Costa et al. (1995) consideram essas rochas como granitóides arqueanos. As amostras são cinza com tonalidade rosada, de granulação média a fina e isótropas, e os afloramentos comumente contém lentes de mobilizados quartzo-feldspáticos e quartzosos.

Em lâmina delgada, as amostras exibem textura granular hipidiomórfica com variação para porfirítica, onde se destacam fenocristais de feldspato potássico e quartzo. Os componentes essenciais são plagioclásio (19-44\%), feldspato potássico (18-51\%) e quartzo (30-39\%), o que define uma composição monzogranítica, segundo o critério de Streckeisen (1976). A biotita é o mineral máfico mais abundante. Os acessórios compreendem alanita, opacos, titanita, zircão e apatita. Os secundários consistem de clorita que parcialmente substitui a biotita, e epídoto e carbonato como produtos de saussuritização do plagioclásio.

TÉCNICAS ANALÍTICAS As análises isotópicas Rb-Sr e $\mathrm{Pb}-\mathrm{Pb}$ foram realizadas no Laboratório de Geologia Isotópica (LGI) do Centro de Geociências da Universidade Federal do Pará.

As amostras coletadas foram pulverizadas ( 80 mesh), homogeneizadas e quarteadas. A separação das frações minerais foi feita com separador magnético tipo Frantz, chapa vibratória e líquidos pesados.

Para o método $\mathrm{Rb}-\mathrm{Sr}$, 50 a $100 \mathrm{mg}$ de amostra foram submetidos a um ataque ácido de $\mathrm{HF}(48 \%)$ e $\mathrm{HNO}_{3}+\mathrm{HClO}_{4}$ $(1: 1)$ concentrados, a quente, anos introdução de um traçador misto, enriquecido em ${ }^{87} \mathrm{Rb} \mathrm{e}^{84} \mathrm{Sr}$ para a determinação dos teores de $\mathrm{Rb}$ e $\mathrm{Sr}$ por diluição isotópica. $\mathrm{O} \mathrm{Rb}$ e o $\mathrm{Sr}$ foram separados e purificados por cromatografia utilizando-se resinas trocadoras de íons DOWEX AG 50x8. Os concentrados finais de $\mathrm{Rb}$ e $\mathrm{Sr}$ foram depositados em filamentos de tungstênio para posterior análise isotópica no espectrômetro de massa. Os brancos de química ficaram abaixo de $5 \mathrm{ng}$ para o $\mathrm{Rb}$ e o Sr.

O procedimento experimental utilizado para o método $\mathrm{Pb}$ - $\mathrm{Pb}$ segue o desenvolvido por Manhès (1982), adaptado às condições do LGI por Rodrigues (1992). A abertura química das frações de rocha total $(500 \mathrm{mg})$ foi feita com $\mathrm{HF}(1 \mathrm{~N})$. O $\mathrm{Pb}$ foi solubilizado com $\mathrm{HBr}(8 \mathrm{~N}$ e $0,5 \mathrm{~N})$ e submetido à separação por cromatografia de resina de troca iônica DOWEX AG 1x8, 200-400 mesh, condicionada com $\mathrm{HBr}$ $(0,5 \mathrm{~N})$. O concentrado final foi depositado em um filamento de rênio para análise isotópica no espectrômetro de massa. Os brancos de química realizados durante o período de análise situaram-se abaixo de $5 \mathrm{ng}$ de $\mathrm{Pb}$.

As análises isotópicas de $\mathrm{Pb}, \mathrm{Rb}$ e $\mathrm{Sr}$ foram realizadas com um espectrômetro de massa VG ISOMASS 54E com monocoletor. As análises do $\mathrm{Sr}$ foram normalizadas a partir da razão ${ }^{84} \mathrm{Sr} /{ }^{88} \mathrm{Sr}=0,1194$. As composições isotópicas do $\mathrm{Pb}$ foram corrigidas do efeito de discriminação de massa utilizando um fator de $0,15 \% \pm 0,03$ por u.m.a., determinado a partir de análises repetidas de NBS982 (equal atoms). O cálculo da idade no diagrama ${ }^{207} \mathrm{~Pb} /{ }^{204} \mathrm{~Pb}$ versus ${ }^{206} \mathrm{~Pb} /{ }^{204} \mathrm{~Pb}$ foi feito segundo York (1969) e Ludwig (1980), enquanto que as idades Rb-Sr foram determinadas com base em York (1967, 1969) e no algoritmo de Williamson (1968) modificado. Os resultados apresentados foram calculados com o desvio padrão de $1 \sigma$.

RESULTADOS ANALÍTICOS Rb-Sr Ortognaisse Arco Verde Duas amostras do Ortognaisse Arco Verde foram selecionadas para determinação geocronológica pelo método Rb-Sr. Para cada amostra, além da rocha total (RT), também foram analisadas frações de biotita (Bt) e de feldspato + quartzo (FQ). Os resultados analíticos estão apresentados na Tabela 1.

A amostra AVR8B forneceu uma idade de $2.095 \pm 142 \mathrm{Ma}$ $(1 \sigma$ ) e Isr de 0,7022 $\pm 0,0010$ com uma MSWD de 15,99 (Fig. 3a), enquanto a amostra AVR10F forneceu uma idade de $2.384 \pm 523 \mathrm{Ma}$ (Io) com uma Isr de 0,7029 $\pm 0,0024$ e uma MSWD de 136 (Fig. 3b). Os altos valores do MSWD indicam que não há alinhamento satisfatório entre as frações FQ, Bt e RT, particularmente na amostra AVR10F, onde a fração de Bt situa-se bem abaixo do alinhamento definido pelas frações de FQ e RT. Não houve, portanto, equilíbrio isotópico entre os minerais das amostras analisadas. Entretanto, como o objetivo principal da aplicação do método $\mathrm{Rb}-\mathrm{Sr}$, neste trabalho, é evidenciar possíveis reaberturas do sistema $\mathrm{Rb}-\mathrm{Sr}$ durante $\mathrm{O}$ Proterozóico, optou-se pela utilização das idades em biotita, mais sensíveis aos efeitos termo-tectônicos.

A biotita das amostras AVR10F e AVR08B forneceu idades aparentes de $1.849 \pm 48 \mathrm{Ma}$ e $2.143 \pm 50 \mathrm{Ma}$, respectivamente, calculadas com valor de $\mathrm{Isr}=0,710$, considerado representativo da razão ${ }^{87} \mathrm{Sr} /{ }^{86} \mathrm{Sr}$ dos minerais de uma rocha arqueana submetida a uma rehomogeneização isotópica no Paleoproterozóico (1,8-2,1 Ga). A escolha deste valor está de acordo com os resultados obtidos por Macambira et al. (1988) a partir de uma isócrona em minerais do Granodiorito Rio Maria.

Monzogranitos tipo Mata Surrão Dessa unidade foram selecionadas duas amostras de monzogranito que afloram no norte da área e duas de monzogranito da porção sul. Além da rocha total (RT), também foram analisadas frações de biotita $(\mathrm{Bt})$ e feldspato + quartzo (FQ).

As duas amostras do monzogranito tipo Mata Surrão (porção norte) alinham-se segundo duas isócronas. Uma (AVR21B) fornece uma idade de $1.978 \pm 84 \mathrm{Ma}(1 \sigma)$, Isr igual a $0,71013 \pm 0,00059$ e MSWD de 4,57 (Fig. 3c). Outra amostra (AVR22A) define uma idade de $2.541 \pm 83 \mathrm{Ma}(1 \sigma)$ Isr de $0,70209 \pm 0,00058$ e MSWD de 2,05 (Fig. 3d). Esses resultados, apesar de relativos a amostras de um mesmo corpo, fornecem idades bastante diferentes, notando-se também a diferença entre os valores de ${ }^{87} \mathrm{Rb} /{ }^{86} \mathrm{Sr}$ das frações de biotita (Tabela 1).

A partir do cálculo de idade aparente em biotita, utilizandose Isr igual a 0,710, obtém-se uma idade de $2.055 \pm 58 \mathrm{Ma}$ para a amostra AVR21B. Para a amostra AVR22A, preferiuse manter a idade isocrônica já que a isócrona obtida mostra um bom alinhamento dos pontos analíticos, incluindo a da fração de biotita.

As duas amostras do monzogranito tipo Mata Surrão coletadas à sul da Serra do Inajá, fornecem duas isócronas Rb-Sr em minerais, cujos resultados analíticos constam da Tabela 1 , com idade de $1.786 \pm 340 \mathrm{Ma}$ (Io) e Isr de 0,888 $\pm 0,089$ $(\mathrm{MSWD}=11,3)$ para a amostra AN01B (Fig. 3e) e de 2.063 $\pm 369(1 \sigma)$ e Isr de $0,734 \pm 0,023($ MSWD = 14,2) para a amostra AB17B (Fig. 3f). A posição dos pontos experimentais, afastados da origem da reta $\left({ }^{87} \mathrm{Rb} /{ }^{86} \mathrm{Sr}>4\right.$ para a amostra $\mathrm{AB} 17 \mathrm{~B}$ e ${ }^{87} \mathrm{Rb} /{ }^{86} \mathrm{Sr}>15$ para a amostra AN01B) provoca, em ambos os casos, um alto valor de desvio para a Isr dessas amostras. Idades aparentes em biotita, calculadas a partir de Isr $=0,710$, fornecem idades de $2.041 \pm 92 \mathrm{Ma} \mathrm{e}$ $2.175 \pm 62 \mathrm{Ma}$ para as amostras AB17B e AN01B, respectivamente (Tabela 1 ).

RESULTADOS ANALÍTICOS Pb-Pb

Ortog-

naisse Arco Verde Cinco amostras desta unidade foram analisadas em rocha total (Tabela 2). No diagrama ${ }^{207} \mathrm{~Pb} /{ }^{204} \mathrm{~Pb}$ (Figura $4 \mathrm{a}$ ), a reta isocrônica 
Tabela 1 - Resultados analiticos Rb-Sr para as amostras estudadas. FQ-feldspato e quartzo; Bt - biotita. Table 1 - Rb-Sr analytical results from studied samples. FQ- feldspar and quartz; Bt- biotite.

\begin{tabular}{|l|c|c|c|c|c|c|c|c|}
\hline \multicolumn{1}{|c|}{ Amostra } & $\mathrm{Rb}_{\mathrm{ppm}}$ & $\mathrm{Sr}_{\mathrm{ppm}}$ & ${ }^{87} \mathrm{Rb} /{ }^{86} \mathrm{Sr}$ & $1 \sigma$ & ${ }^{87} \mathrm{Sr}{ }^{86} \mathrm{Sr}$ & $1 \sigma$ & $\begin{array}{c}\text { Idade (Ma) em } \\
\text { biotita }\end{array}$ \\
\hline Ortognaisse Arco Verde
\end{tabular}

(*) Idade convencional calculada com $\mathrm{I}_{\mathrm{Sr}}=0,710$.

obtida a partir dos pontos experimentais de rocha total fornece uma idade de $2.872 \pm 25 \mathrm{Ma}(1 \sigma)$ com $\mu_{1}=8,3 \pm 0,21$ (onde $\mu_{1}$ é a razão ${ }^{238} \mathrm{U} /{ }^{204} \mathrm{~Pb}$ atual da fonte, cujo valor é calculado a partir do Modelo de Estágio Simples de Holmes \& Houtermans 1946). O MS WD de 1 ,24, indica o bom alinhamento dos pontos experimentais na reta isocrônica

Monzogranitos tipo Mata Surrão Seis amostras de rocha total da porção norte forarn analisadas (Tabela 2). No diagrama ${ }^{207} \mathrm{~Pb} /{ }^{204} \mathrm{~Pb}$ vs. ${ }^{206} \mathrm{~Pb} /{ }^{204} \mathrm{~Pb}$ (Fig. 4b), os pontos analíticos das amostras alinham-se em uma reta que fornece uma idade de $2.894 \pm 19 \mathrm{Ma}(1 \sigma)$ com $\mu_{1}=8,21 \pm 0,17$ e MSWD de 3,54.

Cinco amostras de monzogranitos da porção sul foram selecionadas para análise de rocha total (Tabela 2). No diagrama ${ }^{207} \mathrm{~Pb} /{ }^{204} \mathrm{~Pb}$ vs. ${ }^{206} \mathrm{~Pb} /{ }^{204} \mathrm{~Pb}$ (Fig. $4 \mathrm{c}$ ), as amostras alinham segundo uma reta que fornece uma idade isocrônica de $2.797 \pm 28 \mathrm{Ma}(1 \sigma)$ para $\mu_{1}=8,4 \pm 0,22$ e MSWD de 5,5. É importante assinalar que esta idade é estatisticamente menor (a 2a) que a obtida para o Monzogranito tipo Mata Surrão da porção norte da região de Redenção.

DISCUSSÃ O E INTERPRETAÇÕES Os resultados geocronológicos obtidos pelo método $\mathrm{Pb}-\mathrm{Pb}$ aplicado em rochas ígneas arqueanas deformadas têm sido interpretados alternativamente como idades de cristalização ou de rehomogeneização isotópica durante o metamorfismo e a deformação. Muitas vezes é difícil diferenciar os eventos (magmáticos/metamórficos) devido ao pequeno intervalo de tempo entre a formação dos granitóides e seu retrabalhamento (Taylor et al. 1980, Bickle et al. 1983, Kalsbeek et al. 1984).

A interpretação da idade $\mathrm{Pb}-\mathrm{Pb}$ do Ortognaisse Arco Verde é bastante dificultada pelas divergências quanto a sua gênese e evolução. Para Althoff et al. (1995) o Tonalito Arco Verde é um corpo sincinemático a um evento de encurtamento horizontal homogêneo, sendo as texturas deformacionais adquiridas ainda no estágio magmático. Nesse caso, a idade $\mathrm{Pb}-\mathrm{Pb}$ de $2.872 \pm 25 \mathrm{Ma}$ deve ser interpretada como a de cristalização, sendo o Ortognaisse Arco Verde contemporâneo ao magmatismo granítico associado aos greenstone belts da região de Rio Maria - Serra dos Gradaús (Granodioritos Rio Maria e Cumaru, Trondhjemito Mogno, Monzogranitos Xinguara e Mata Surrão). Os resultados geocronológicos aqui obtidos inviabilizam a correlação com o Tonalito Arco Verde da Região de Rio Maria, cuja idade U-Pb em zircão é de $2.957+25 /-21$ Ma (Macambira \& Lancelot, no prelo). A denominação de Ortognaisse Arco Verde, sugerida por Araújo et al. (1994) e Araújo \& Costa (1994) para as rochas tonalíticas da região de Redenção anteriormente englobadas no Complexo Xingu deve, portanto, ser restrita à região de Rio Maria. É importante ressaltar que não existe continuidade física entre as rochas tonalíticas das regiões de Rio Maria e Redenção, pois estas estão separadas pelos granitóides Guarantã e Rio Maria, a sul da vila de Marajoara (Althoff et al. 1991, 1995).

Alternativamente, a idade $\mathrm{Pb}-\mathrm{Pb}$ de $2.872 \pm 25 \mathrm{Ma}$ pode ser relacionada a um episódio de retrabalhamento das rochas tonalíticas responsável, segundo Costa et al (1995), pelas estruturas deformacionais, permanecendo indefinida a idade do protólito ígneo. Essa interpretação implica em que o 

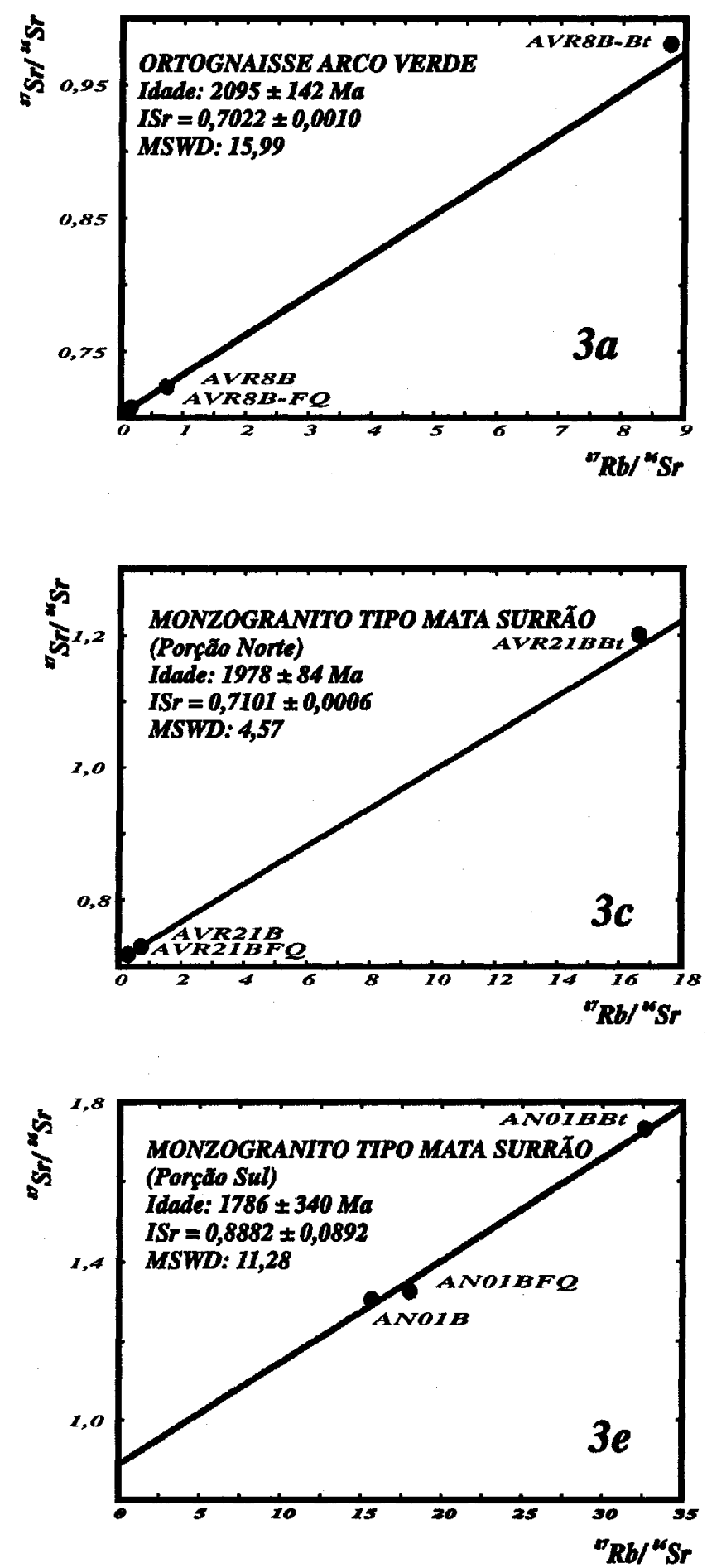
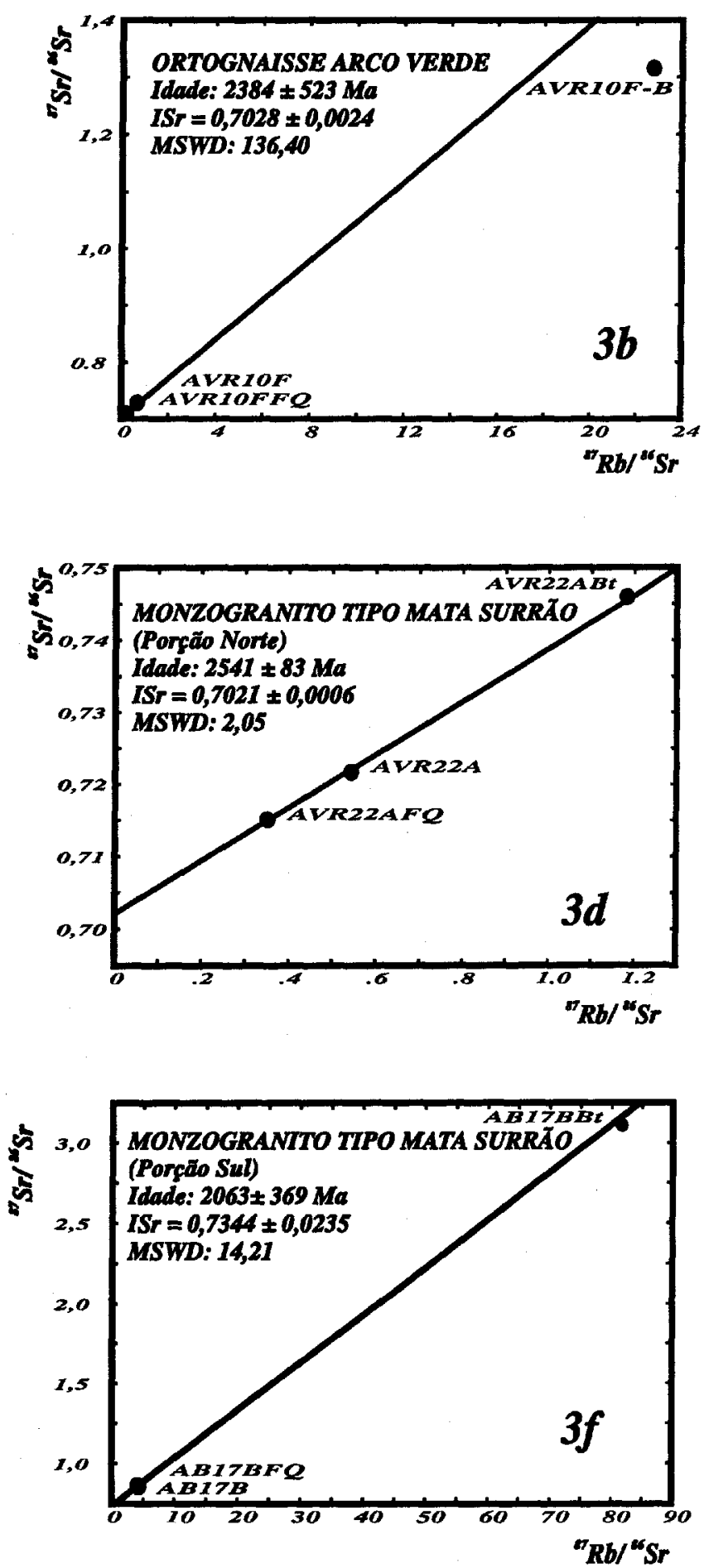

Figura 3 - Diagrama isocrônico das frações de rocha total e minerais dos granitóides arqueanos da região de Redenção, (a) amostra AVR8B do Ortognaisse Arco Verde, (b) amostra AVR10F do Ortognaisse Arco Verde, (c) amostra AVR21B do monzogranito tipo Mata Surrão da porção Norte da região de Redenção, (d) amostra A V22A do monzogranito tipo Mata Surrão da porção Norte da região de Redenção, (e) amostra AN01B do Monzogranito tipo Mata Surrão da porção Sul da região de Redenção, (f) amostra AB17B do Monzogranito tipo Mata Surrão da porção Sul da região de Redenção.

Figure $3-\mathrm{Rb}$-Sr isochron diagram on whole rock and mineral fraction from the Archean granitoids of the Redenção region, (a) AVR8B sample of Arco Verde Gneiss, (b) AVR10F sample of Arco Verde orthogneiss. (c) AVR21B sample of Mata Surrão Monzogranite of the northern portion of the Redenção region, (d) AVR22A sample of Mata Surrão Monzogranite of the northern portion of Redenção region, (e) AN01B sample of Mata Surrão Monzogranite of southern portion of the Redenção region, (f) AB17B sample of Mata Surrão Monzogranite of the southern portion of Redenção region 
sistema $\mathrm{Pb}-\mathrm{Pb}$ tenha sido completamente rehomogeneizado em escala quilométrica, haja visto a distância entre os pontos analisados. Tal processo necessita de altos gradientes de pressão e temperatura e a idade de $2.872 \pm 25 \mathrm{Ma}$ indicaria, portanto, o episódio principal de implantação, na área, do Cinturão Pau d'Arco.

O bom alinhamento dos pontos experimentais na reta isocrônica $(\mathrm{MSWD}=1,24)$ e o fato das amostras datadas serem provenientes de porções isotrópicas e portanto isentas de feições marcantes de deformação, não favorece a interpretação da idade $\mathrm{Pb}-\mathrm{Pb}$ como de retrabalhamento. Diante disso, prefere-se considerar a idade de $2.872 \pm 25 \mathrm{Ma}$ como a de cristalização do protólito do Ortognaisse Arco Verde.

A idade de $2.894 \pm 19 \mathrm{Ma}$ obtida pelo método $\mathrm{Pb}-\mathrm{Pb}$ no monzogranito tipo Mata Surrão da porção norte da região de Redenção é similar as idades U-Pb e $\mathrm{Pb}-\mathrm{Pb}$ em torno de 2,87 Ga do Granito Mata Surrão e dos granitóides arqueanos associados aos greenstone belts da região de Rio Maria (Macambira 1992, Lafon et al. 1994, Pimentel \& Machado 1994).

As amostras datadas deste monzogranito apresentam uma textura ígnea preservada com características petrográficas, estruturais e idade similares aos demais granitos arqueanos da região de Rio Maria, em especial o Granito Mata Surrão
(Duarte et al. 1991), permitindo interpretar a idade obtida como a de cristalização magmática do mesmo.

As idades obtidas para as rochas tonalíticas e monzograníticas da porção norte da região de Redenção são semelhantes dentro da margem de erro, caracterizando a ocorrência de granitóides arqueanos na região de Redenção e sugerindo que o magmatismo gerador dessas rochas se estendeu desde a região de Rio Maria até, pelo menos, a porção norte da região de Redenção.

A idade de $\mathrm{Pb}-\mathrm{Pb}$ em rocha total de $2.797 \pm 28 \mathrm{Ma}$ do Monzogranito tipo Mata Surrão na porção sul da região de Redenção é superior a obtida por Cunha et al (1981) pelo método $\mathrm{Rb}-\mathrm{Sr}(1,73 \mathrm{Ga})$ na Suíte Rio Dourado. Essas rochas, a exemplo da porção norte da região estudada, são isotrópicas com textura ígnea preservada. Assim, a idade aqui obtida é interpretada como a de formação dessa unidade, confirmando que esse corpo não pertence ao magmatismo proterozóico da Suíte Intrusiva Rio Dourado. Contudo, a idade menor do monzogranito da porção sul sugere a ocorrência de, pelo menos, dois eventos magmáticos arqueanos distintos na região de Redenção.

Os resultados aqui alcançados mostram que, na região de Redenção, o período entre 2,80 a $2,89 \mathrm{Ga}$ foi marcante na

Tabela 2 - Resultados analíticos Pb-Pb para as amostras estudadas.

Table $2-\mathrm{Pb}-\mathrm{Pb}$ analytical results from studied samples.

\begin{tabular}{|c|c|c|c|c|c|c|}
\hline Amostra & ${ }^{206} \mathrm{~Pb} /{ }^{204} \mathrm{~Pb}$ & $1 \sigma$ & ${ }^{207} \mathrm{~Pb} /{ }^{204} \mathrm{~Pb}$ & $1 \sigma$ & ${ }^{208} \mathrm{~Pb} /{ }^{204} \mathrm{~Pb}$ & $1 \sigma$ \\
\hline \multicolumn{7}{|c|}{ Ortognaisse Arco Verde } \\
\hline AVR8B & 19,272 & 0,012 & 15,837 & 0,015 & 36,203 & 0,044 \\
\hline AVR10B & 20,465 & 0,014 & 16,095 & 0,016 & 38,173 & 0,050 \\
\hline AVR10F & 21,845 & 0,015 & 16,390 & 0,016 & 37,182 & 0,045 \\
\hline AVR15B & 22,565 & 0,014 & 16,538 & 0,015 & 41,637 & 0,050 \\
\hline AVR15D & 25,754 & 0,019 & 17,168 & 0,019 & 47,526 & 0,067 \\
\hline \multicolumn{7}{|c|}{ Monzogranito tipo Mata Surrão da porç̧ão norte da Região de Redenção } \\
\hline AVR22B & 17,382 & 0,018 & 15,439 & 0,014 & 38,116 & 0,046 \\
\hline AVR22A & 22,021 & 0,016 & 16,388 & 0,018 & 43,910 & 0,059 \\
\hline AVR21A & 22,513 & 0,014 & 16,513 & 0,015 & 39,899 & 0,048 \\
\hline AVR21B & 23,832 & 0,015 & 16,800 & 0,015 & 43,303 & 0,053 \\
\hline AVR21D & 25,767 & 0,024 & 17,135 & 0,021 & 42,063 & 0,059 \\
\hline AVR22C & 30,681 & 0,019 & 18,220 & 0,017 & 49,389 & 0,059 \\
\hline \multicolumn{7}{|c|}{ Monzogranito tipo Mata Surrão da porção sul da Região de Redenção } \\
\hline $\mathrm{AB} 17 \mathrm{C}$ & 16,690 & 0,014 & 15,366 & 0,017 & 47,321 & 0,070 \\
\hline $\mathrm{AB} 17 \mathrm{~A}$ & 18,185 & 0,012 & 15,646 & 0,015 & 48,670 & 0,064 \\
\hline AB17B & 18,373 & 0,012 & 15,671 & 0,015 & 46,297 & 0,057 \\
\hline AN01B & 25,093 & 0,015 & 17,044 & 0,016 & 45,510 & 0,057 \\
\hline ANO1H & 27,447 & 0,024 & 17,433 & 0,019 & 50,040 & $0 ; 071$ \\
\hline
\end{tabular}


evolução geológica regional, constituindo um importante registro cronológico em toda a PMC, já que idades semelhantes também ocorrem na Serra dos Carajás (Machado et al. 1991), em Rio Maria (Macambira \& Lancelot 1991, Pimentel \& Machado 1994, Lafon et al 1994), na Serra dos Gradaús (Lafon \& Scheller 1994) e na região de Tucumã (Avelar et al 1995). Até o momento, não há registro de idades mais antigas que 3,0 Ga na região de Redenção, nem em torno de 2,97 Ga, como em Rio Maria ou na Serra dos Gradaús (Macambira
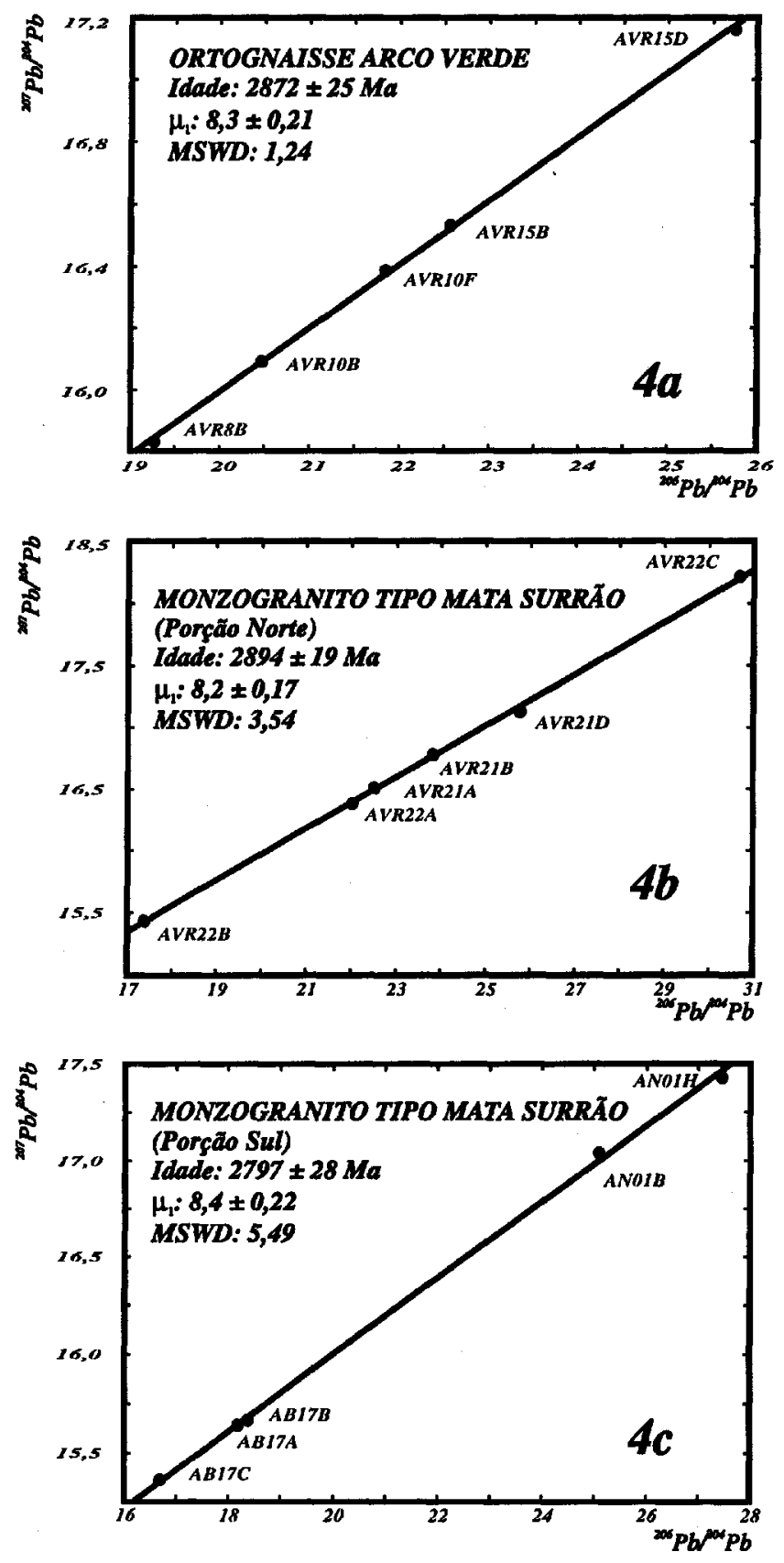

Figura 4 - Diagrama isocrônico $\mathrm{Pb}-\mathrm{Pb}$ em rocha total dos granitóides arqueanos da região de Redenção, (a) Ortognaisse Arco Verde, (b) Monzogranito tipo Mata Surrão da porção Norte da região de Redenção, (c) Monzogranito tipo Mata Surrão da porção Sul da região de Redenção. Figure $4-\mathrm{Pb}-\mathrm{Pb}$ isochron diagram on whole rock from the Archean granitoids of the Redenção region, (a) samples from the Arco Verde orthogneiss. (b) samples from the Mata Surrão Monzogranite of the northern portion of the Redenção region, (c ) samples from the Mata Surrão Monzogranite of the southern portion of the Redenção region
1992, Pimentel \& Machado 1994). Porém, não se deve esquecer as limitações do método $\mathrm{Pb}-\mathrm{Pb}$ em áreas metamórficas e deformadas, que pode registrar os eventos termo-tectônicos, ao invés da idade de cristalização.

Os valores de $\mu_{1}$ das rochas estudadas (Tonalito Arco Verde: $8,3 \pm 0,21$; monzogranito tipo Mata Surrão da porção norte da região de Redenção: 8,2 $\pm 0,17$ e monzogranito tipo Mata Surrão a sul da Serra do Inajá: $8,2 \pm 0,17$ ), podem ser considerados similares entre si e ao valor de 8,2 $\pm 0,11$ obtido no Monzogranito tipo Mata Surrão da região de Rio Maria $\left(\mu_{1}\right.$ $=8,2 \pm 0,11)$ por Lafon et al (1994). Tal similaridade indica uma possível fonte comum para as mesmas.

As idades $\mathrm{Rb}-\mathrm{Sr}$ em rocha total de 2,7 Ga e 2,75 Ga (lanhez et al. 1980; Cunha et al 1981) anteriormente admitidas como as de formação do Complexo Xingu na região de Redenção passam, pois, a ser aceitas como idades mínimas de reabertura do sistema $\mathrm{Rb}-\mathrm{Sr}$ das rochas granitóides investigadas. Uma situação comparável já foi observada nas regiões de Rio Maria e Serra dos Gradaús onde o cronômetro $\mathrm{Rb}$-Sr foi sistematicamente perturbado após a cristalização, fornecendo idades entre 2,75 - 2,50 Ga para rochas formadas entre 2,87 e 2,97 $\mathrm{Ga}$. A reabertura do sistema $\mathrm{Rb}-\mathrm{Sr}$ foi interpretada como o efeito dos eventos tectono-metamórficos que afetaram as rochas da PMC no final do Arqueano (Macambira \& Lafon 1995). Na região de Redenção, as idades $\mathrm{Rb}-\mathrm{Sr}$ de 2,70-2,75 Ga devem provavelmente também representar o limite inferior das idades dos eventos termo-tectônicos que conduziram a estruturação da região no final do Arqueano. Assim, como em toda a Província Mineral de Carajás, o método $\mathrm{Rb}-\mathrm{Sr}$ em rocha total deve ser visto apenas como um indicador dos eventos termo-tectônicos que afetaram a área no final do Arqueano, limitando-se a proporcionar uma idade mínima da formação das rochas. Além disso, também não se deve descartar a possibilidade dos efeitos térmicos ligados às intrusões de granitos anorogênicos terem contribuído para a reabertura do sistema $\mathrm{Rb}-\mathrm{Sr}$ das rochas arqueanas da Província de Carajás e de Redenção, produzindo idades sem sentido geológico.

As idades convencionais $\mathrm{Rb}-\mathrm{Sr}$ da biotita situam-se no intervalo de idades anteriormente obtidas pelo método $\mathrm{K}-\mathrm{Ar}$ em minerais $(2,2-1,71 \mathrm{Ga})$ nas rochas do Complexo Xingu na Folha SC.22 Tocantins (Bezerra et al. 1982). Idades similares também foram obtidas pelos métodos Rb-Sr, K-Ar e Ar-Ar em minerais das rochas arqueanas da região de Rio Maria (Macambira et al 1988, Macambira et al 1990) e de Carajás (Gomes et al 1975, Tassinari et al 1982, Renneeía/. 1988), mostrando que temperaturas superiores a $300-350{ }^{\circ} \mathrm{C}$, que é a temperatura de fechamento do sistema $\mathrm{Rb}-\mathrm{Sr}$ da biotita (Jàger 1979) foram alcançadas. Essas idades foram relacionadas à influência do Ciclo Transamazônico nas unidades arqueanas da PMC (Gomes et al 1975, Bezerra et al 1982, Tassinari et al 1982). Entretanto, a ausência de evidências geológicas desse Ciclo na PMC e a sua não detecção pelos métodos U-Pb em titanita e monazita e K-Ar e Ar-Ar em anfibólio (Macambira et al 1988, Renne et al 1988, Machado et al 1991) levaram a reinterpretar essas idades como efeitos térmicos do magmatismo proterozóico. A ausência de alinhamento satisfatório das isócronas de minerais é provavelmente devida às transformações que afetaram principalmente a biotita e os feldspatos. A amostra AVR22A do Monzogranito Mata Surrão da porção norte da região de Redenção forneceu uma idade isocrônica em minerais de $2.541 \pm 83 \mathrm{Ma}$, similar à de 2.541 \pm 74 Ma obtida pelo mesmo método em rocha total do Monzogranito na região de Rio Maria (Duarte et al 1991). Na região da Serra dos Gradaús, Lafon et al (1990) também obtiveram uma idade isocrônica $\mathrm{Rb}-\mathrm{Sr}$ em minerais de 2,58 $\mathrm{Ga}$, similar à idade $\mathrm{Rb}-\mathrm{Sr}$ em rocha total do mesmo.

Isto mostra que os efeitos térmicos do magmatismo proterozóico não afetaram uniformemente toda a região de Redenção, ou, mais provavelmente, que o sistema $\mathrm{Rb}$-Sr teve um 
comportamento diferenciado durante o reaquecimento proterozoico. No caso da biotita da amostra AVR22A, a razão ${ }^{87} \mathrm{Rb} /{ }^{86} \mathrm{Sr}$ de 1,18 é bastante inferior à das outras $(8,77$ $\left.{ }^{87} \mathrm{Rb} /{ }^{86} \mathrm{Sr} 81,61\right)$, com teor mais baixo de $\left.\mathrm{Rb}<200 \mathrm{ppm}\right)$ e, sobretudo, de Sr demasiado elevado ( $\approx 500 \mathrm{ppm})$ para esse mineral. Observa-se que a biotita dessa amostra apresenta uma alteração mais intensa para clorita. É comum também a presença de epídoto na biotita, o que poderia explicar os teores de $\mathrm{Rb}$ e $\mathrm{Sr}$ observados. O epídoto da biotita poderia ter facüitado o comportamento em sistema fechado, acomodando o $\mathrm{Sr}$ radiogênico eventualmente liberado pela biotita. De qualquer modo, a idade dessa amostra sugere que o sistema $\mathrm{Rb}-\mathrm{Sr}$ resistiu melhor aos efeitos do reaquecimento proterozóico.

CONCLUSÕES Os resultados obtidos neste trabalho, junto com os dados geocronológicos já existentes, permitem inserir algumas referências cronológicas para a evolução arqueana e proterozóica da região de Redenção e levantam algumas questões a serem ainda esclarecidas.

A idade $\mathrm{Pb}-\mathrm{Pb}$ em rocha total de $2.872 \pm 25 \mathrm{Ma}$ do Ortognaisse Arco Verde é interpretada como a de cristalização, não sendo totalmente descartada a possibilidade de se tratar de uma idade rejuvenescida, correspondente à época de retrabalhamento. De qualquer forma, esse resultado demonstra a necessidade de definir uma nova denominação para as rochas tonalíticas da região de Redenção e restringir o termo Tonalito Arco Verde apenas à região de Rio Maria.

As idades $\mathrm{Pb}-\mathrm{Pb}$ de $2.894 \pm 28 \mathrm{Ma}$ dos Monzogranitos tipo Mata Surrão (porção norte da região de Redenção) e $2.797 \pm$ $28 \mathrm{Ma}$ (sul da Serra do Inajá) são também interpretadas como as de cristalização dessas unidades, evidenciando a existência de pelo menos dois eventos magmáticos distintos no Ar- queano na região de Redenção. O primeiro evento, situado no intervalo entre 2,89-2,87 Ga, é similar ao obtido pelo método $\mathrm{U}-\mathrm{Pb}$ em zircão e $\mathrm{Pb}-\mathrm{Pb}$ em rocha total em granitóides dos terrenos granito-greenstones de Rio Maria. O segundo, situado a 2,80 Ga, é caracterizado na área ao sul da Serra do Inajá.

Os resultados obtidos pelo método $\mathrm{Pb}-\mathrm{Pb}$ em rocha total não evidenciam, até o presente, na região de Redenção idades de 2,97 Ga, obtidas para a formação do Tonalito Arco Verde na região de Rio Maria, não sendo também encontrados indícios de rochas mais velhas que 3,0 Ga. Entretanto, esses dados mostram que o evento magmático de 2,87 Ga foi fundamental na história geológica da região sul do Pará.

Os valores de $\mathrm{u} i$ das rochas arqueanas estudadas sugerem uma evolução a partir de uma fonte provavelmente comum para o ortognaisse tonalítico e os monzogranitos tipo Mata Surrão. Estes valores, apesar de um pouco superiores aos tipicamente mantélicos (Dupré \& Arndt 1990), não favorecem uma derivação a partir de uma crosta continental diferenciada mais antiga.

As idades $\mathrm{Rb}-\mathrm{Sr}$ refletem a reabertura do sistema $\mathrm{Rb}-\mathrm{Sr}$ provocada pelos eventos tectono-metamórficos do final do Arqueano e pelo evento térmico do Paleoproterozóico responsável pela intrusão dos granitóides anorogênicos.

Agradecimentos À FINEP e CNPq pelo apoio financeiro, aos geólogos Agildo Pina Neves e Armínio Gonçalves Vale (CPRM/SUREG-Belém) pelo apoio nos trabalhos de campo, ao Dr. Thomas Scheller pelo auxílio no tratamento analítico das amostras, ao Dr. Moacir Macambira e aos dois relatores anônimos pela revisão crítica do manuscrito e à equipe técnica do LGI pela colaboração durante as análises.

\section{APENDICE}

Coordenadas geográficas das amostras datadas. Monzogranito tipo Mata Surrão (norte): amostras AVR21A, AVR21B e AVR21D: 5000'24"E/08 09'36"N; amostras AVR22A, AVR22B e AVR22C: 50³3'25"E /08 11'21"N. Monzogranito tipo Mata Surrão (sul): amostras AN01B e AN01H:
50'31'42"E/0900'00"N; AB17A, AB17B e AB17C: $50^{\circ} 31^{\prime} 30^{\prime \prime} \mathrm{E} / 09^{\circ} 04^{\prime} 54^{\prime \prime N}$. Ortognaisse Arco Verde: amostras AVR08A e AVR08B: 50²4'29"E/08 $08^{\prime} 45^{\prime \prime N}$; amostras AVR10B e AVR10F: 50²3'35"E/08 $07^{\prime} 26^{\prime \prime N}$; amostras AVR15B e AVR15D: 50²6'03"E/08 $10^{\prime} 52^{\prime \prime N}$.

\section{REFERÊNCIAS}

ALMEIDA, F.F.M. 1967. Origem e evolução da Plataforma Brasileira. Rio de Janeiro, DNPM/DGM. 36p. (Boletim 241)

ALTHOFF, F.J.; DALL'AGNOL, R.; SOUZA, Z.C. 1991. Região de Marajoara - SE do Pará: prolongamento dos terrenos Arqueanos de Rio Maria ou retrabalhamento? In: SIMPÓSIO DE GEOLOGIA DA AMAZÔNIA, 3, Belém, 1991. Anais... Belém, SBG. p.130-141.

ALTHOFF, J.F.; BARBEY, P.; BOULLIER, R.; DALL'AGNOL, R. 1995. Composição e estrutura dos granitóides arqueanos da região de Marajoara. Boletim do Museu Paraense Emílio Goeldi. 7:5-26.

ARAÚJO, O.J.B. \& COSTA, J.B.S. 1994. Correlações entre as principais unidades rochosas da região sudeste do Pará na área do Programa Grande Carajás. In: CONGRESSO BRASILEIRO DE GEOLOGIA, 38, Balneário Camboriú, 1994. Anais... Balneário Camboriú, SBG. v. 2, p.65-66.

ARAÚJO, O.J.B.; MACAMBIRA, E.M.B.; VALE, A.G.; COSTA, E.J.S.; SANTOS, A.; PENA FILHO, J.I.C.; NEVES, A.P.; JOÃO, X.S.J.; COSTA, J.B.S. 1994. Primeiras integrações das investigações geológicas do Programa Grande Carajás na Região SSE do Estado do Pará. In: SIMPÓSIO DE GEOLOGIA DA AMAZÔNIA, 4., Belém, 1994. Resumos. Belém, SBG. p.299-301.

ARAÚJO, O.J.B.; MAIA, R.; JORGE JOÃO, X.S.; COSTA, J.B.S. 1988. A Megaestruturação arqueana da Folha Serra do Carajás. In: CONGRESSO LATINO AMERICANO DE GEOLOGIA, 7, Belém, 1988. Anais... Belém, SBG. v.1. p. 324-333.
AVELAR, V.G; LAFON, J.M; MACAMBIRA, E.M.B. 1995. Geocronologia $\mathrm{Pb}-\mathrm{Pb}$ em zircão do magmatismo da região de Tucumã, Amazônia Oriental, Brasil. In: CONGRESSO BRASILEIRO DE GEOQUÍMICA, 5, Niterói, 1995. Anais... Niterói, SBGq. CD-Rom.

BARBOSA, A.A.; LAFON, J.M.; NEVES.A.P. ;VALE, A.G. 1995. Geocronologia Rb-Sr e Pb-Pb do Granito Redenção, SE do Pará: implicações para o magamatismo proterozóico da região de Redenção. Boletim do Museu Paraense Emílio Goeldi, 7: 147-164.

BEZERRA, P.E.L.; CUNHA, B.C.C.; MONTALVÃO, R.M.G. de; IANHEZ, A.C.; POTIGUAR, L.A.T.; PITTHAN, A.H.L. 1982. Geocronologia da extremidade sudeste da Plataforma Amazônica e da Faixa de Dobramentos Araguaia - Tocantins. In: SIMPÓSIO DE GEOLOGIA DA AMAZÔNIA, 1, Belém, 1982. Anais... Belém. SBG,v.1,p.9-24.

BICKLE, M.J.; CHAPMAN, H.J.; BETTENAY, L.F.; GROVES, D.I. 1983. Lead ages, reset rubidium-strontium ages and implications for the Archean crustal evolution of Diemals area, Central Yilgarn Block, Western Australia. Geoch. Cosmoch. Acta, 47: 907-914.

COSTA, J.B.S.; TEIXEIRA, N.P.; PINHEIRO, R.V.L.; BEMERGUY, R.L. 1990. Os Sistemas estruturais transcorrentes do Cinturão Itacaiúnas na região de Curianópolis, leste do Estado do Pará. In: CONGRESSO BRASILEIRO DE GEOLOGIA, 36., Natal, 1990. Anais... Natal, SBG v. 5 , p. $2345-2357$.

COSTA, J.B.S.; PINHEIRO, R.V.L.; JOÃO, J.X.S. 1991. Esboço estrutural do Proterozóico Médio da Amazônia oriental. Boletim do Museu Paraense Emílio Goeldi, 3: 9-24. 
COSTA, J.B.S.; ARAÚJO, O.J.B.; SANTOS, A.; JOÃO, X.S.J.; MACAMBIRA, M.J.B.; LAFON, J.M. 1995. A Provínca Mineral de Carajás: Aspectos tectono-estruturais, estratigráficos e geocronológicos. Boletim do Museu Paraense Emílio Goeldi. 7:199-235.

CUNHA, B.B.C.; POTIGUAR, L.A.T.; IANHEZ, A.C.; BEZERRA, P.E.L.; PITHAM, J.H.L.; SOUZA Jr., J.J.; MONTALVÃO, R.M.G.; SOUZA, A.M.; HILDRED, P.R.; TASSINARI, C.C.G. 1981. Geologia, geomorfologia, pedologia, vegetaç̃o e uso potencial da Terra.. In: BRASIL. Projeto RADAMBRASIL. Folha SC.22 Tocantins. Rio de Janeiro. Cap.1, p.21-196. (Levantamento de Recursos Naturais, 22).

DOCEGEO (Rio Doce Geologia e Mineração). 1988. Revisão litoestratigráfica da Província Mineral de Carajás, Pará. In: CONGRESSO BRASILEIRO GEOLOGIA, 35., Belém, 1988. Anexo aos Anais. Belém, SBG. p. 11-54.

DUARTE, K.D.; PEREIRA, E.D.; DALL'AGNOL, R.; LAFON, J.M. 1991. Geologia e geocronologia do Granito Mata Surrão - sudoeste de Rio Maria (Pa). In: SIMPÓSIO DE GEOLOGIA DA AMAZÔNIA 31, Belém, 1991. Anais... Belém, SBG. p.7-20.

DUPRE, B. \& ARNDT, N.T. 1990. Pb isotopic compositions of Archean komatiites and sulfides. Chemical Geology 85: 35-56.

GOMES, C.B.; CORDANI, U.G.; BASEI, M.A.S. 1975. radiometric ages from the Serra dos Carajás area, Northern Brazil. Geological Soc. of. Amer. Bull., 86:939-942.

HIRATA, W.K.; RIGON, J.C.; KADEKARU, K.; CORDEIRO, A.A.C.; MEIRELLES, E.M. 1982. Geologia regional da Província Mineral de Carajás. In: SIMPÓSIO DE GEOLOGIA DA AMAZÔNIA, 1, Belém, 1982. Anais.. Belém, SBG. v.l, p. 100-108.

HOLMES, A. 1946. An estimate of the age of the earth. Nature, 157:680-684.

HOUTERMANS, F.G. 1946. Die isotopenhàufigkeiten im natúrlichen Blei und das Alter des Urans. Naturwissenschaften, 33: 185-186

HUHN, S.R.B.; SANTOS,A.B.S.; AMARAL, A.F.; LENDSHAN, E.J.; GOUVÊA, J.L.; MARTINS, L.P.B; MONTALVÃO, R.M.G.; COSTA, V.G. 1988. Terreno "granito greenstone" da região de Rio Maria sul do Pará. In: CONGRESSO BRASILEIRO DE GEOLOGIA, 35, Natal, 1993. Anais... Recife, SBG. v.3, p.1438-1452.

IANHEZ, A.C.; CUNHA, B.C.C.; BEZERRA, P.E.L.; POTIGUAR, L.A.T.; PITTHAN, J.H.L.; MONTALVÃO, R.M.G. 1982. Vulcano-plutonismo da extremidade sudeste da Plataforma Amazônica. In: SIMPÓSIO DE GEOLOGIA DA AMAZÔNIA, 1, Belém, 1982. Anais... Belém, SBG. v.1, p.128-146.

IANHEZ, A.C.; SOUZA, A.M.S. de; MONTALVÃO, R.M.G. de. 1980. Geologia da seqüência vulcano-sedimentar da Serra do Inajá - Santana do Araguaia. In: CONGRESSO BRASILEIRO DE GEOLOGIA, 31, Camboriú, 1990. Anais... Camboriú, SBG. v.5, p.2918-2928.

JAGER, E. 1979. Introduction to geochronology. In: JAGER, E \& HUNZIKER, J.C. Lectures In isotope Geology. Berlin Heideber. New York. Springer-Verlag 312p.

KALSBEEK, F.; TAYLOR, P.N.; HENRIKSEN, N. 1984. Age of rocks, structures, and metamorphism in the Nagssugtoqidian mobile belt, West Greenland - field and $\mathrm{Pb}$-isotope evidence. Canadian Journal of Earth Science, 21:1126-1131.

LAFON, J.M. \& SCHELLER, T.I994. Geocronologia $\mathrm{Pb} / \mathrm{Pb}$ em zircões do Granodiorito Cumaru, Serra dos Gradaús, Pa. In: SIMPÓSIO DE GEOLOGIA, 4,1994. Anais... Belém, SBG. P.321-324

LAFON, J.M.; MACAMBIRA, J.B.; PEREIRA, E.D.; SCHELLER, T. 1990 Geocronologia $\mathrm{Rb}-\mathrm{Sr}$ em rochas totais e minerais do Granodiorito Cumaru, Serra dos Gradaús, Pa. In: CONGRESSO BRASILEIRO DE GEOLOGIA, 36., Natal, 1990. Anais... Natal, SBG. v.6. p. 2929-2940.

LAFON, J.M.; RODRIGUES, E.; DUARTE, K.D. 1994. Lê Granite Mata Surrão: Un magmatisme monzogranitique contemporain des associations tonalitiques trondhjémitiques granodioritiques archéennes de la Region de Rio Maria (Amazonie Orientale). C. R. Acad. Sci. Paris. 318: 643-649.

LAFON, J.M.; RODRIGUES.E.; MACAMBIRA, E.M.B.; PEREIRA, E.D. 1995. Magmatisme anorogénique du Protérozoique inférieur dans la region de São Félix do Xingu - Tucumã (Amazonie Orientale, Brésil). Nouvelles données géochronologiques. C. R. Acad. Sci. Paris. 320: 937-944.

LUDWIG, K.R.1980. Calculation of uncertainities of Pb-U isotope data. Earth Planet. Sci. Letters. 46: 212-220.
MACAMBIRA, M.J.B. 1992. Chronologic U-Pb, Rb-Sr, K-Ar et croissance de la croüte continentale dans I'Amazonie du Sud-Est; exemple de la region de Rio Maria, Province de Carajás, Brésil. Montpellier. 212p. (Dissertação de Doutorado, Univ. Montpellier II).

MACAMBIRA, M.J.B. \& LAFON, J.M. 1995. Geocronologia da Província Mineral de Carajás; síntese dos dados e novos desafios. Boletim do Museu Paraense Emílio Goeldi. 7:263-288.

MACAMBIRA, M.J.B. \& LANCELOT, J. 1991. Em busca do embasamento arqueano da região de Rio Maria, sudeste do Estado do Pará. In SIMPÓSIO DE GEOLOGIA DA AMAZÔNIA, 3, Belém, 1991. Resumos... Belém. SBG. p.49-58.

MACAMBIRA, M.J.B. \& LANCELOT, J. Time constraints for the formation of the Archean Rio Maria crust, southeastern Amazonian Craton, Brazil. International Geology Review, no prelo.

MACAMBIRA, M.J.B.; LAFON, J.M.; DALL'AGNOL, R.; JOÃO, X.S.J.; COSTI, H.T. 1990. Geocronologia da granitogênese da Província Amazônia Central brasileira: uma revisão. Rev. Brasil. Geoci., 20: 258-266.

MACAMBIRA, M.J.B.; PEREIRA, E.D.; KAWASHITA, K.; MEDEIROS, H. 1988. Contribuição à história tectono-termal da região da Serra das Andorinhas (SE do Estado do Pará). In: CONGRESSO BRASILEIRO GEOLOGIA, 35, 1988. Belém. Anais... Belém, SBG. v.3, p. 1468-1477.

MACHADO, N.; LINDENMAYER, Z.; KROGH, T.E.; LINDENMAYER, D. 1991. U-Pb Geochronology of Archean magmatism anb Basement reactivation in the Carajás area, Amazon Shield Brazil. Precamb. Res. 49:329-355.

MANHĖS, G. 1982. Développement de I'ensemble chronometrique $U$-Th-Pb. Contribution à la chronologie initiale do système solaire. Paris, 249p. (These de doctorat d'etat, Université de Paris VII)

PIMENTEL, M.M. \& MACHADO, N. 1994. Geocronologia U-Pb do terreno granito greenstone de Rio Maria - Pará. In: CONGRESSO BRASILEIRO DE GEOLOGIA, 38, Balneário de Camboriú, 1994. Resumos. Balneário de Camboriú, SBG, v. 2, p. 390 -391.

RENNE, P.R.; ONSTOTT, T.C.; JOÃO, X.S.J. 1988. 40Ar/39Ar and paleomagnetic results from the Guaropé shield; further implications for the nature of Middle Late Proterozoic mobile belts of Gondwanaland. In: CONGRESSO LATINOAMERICANO DE GEOLOGIA, 7, Belém, 1988. Anais... Belém, SBG. p. 348-362.

RODRIGUES, E.M.S. 1992. Implantação da metodologia $\mathrm{Pb}-\mathrm{Pb}$ em rocha total: exemplos de aplicação na Província Mineral de Carajás (Pa). Belém, 128p. (Dissertação de Mestrado, Centro de Geociências da Universidade Federal do Pará)

SILVA, G.G; LIMA, M.I.C.; ANDRADE, A.R.F; ISSLER, R.S ; GUIMARÃES, G. 1974. In: BRASIL. Projeto RADAMBRASIL. Folha SC.22 Tocantins; Geologia, geomorfologia, pedologia, vegetação e uso potencial da Terra. Rio de Janeiro. Cap.1, p.1-143. (Levantamento de Recursos Naturais, 4).

STRECKEISEN, A. 1976. To each plutonic rock its Proper name. Earth Science Reviews, 12: 1-33.

TASSINARI, C.C.G.; SIGA Jr., O.; TEIXEIRA, W. 1984. Épocas metalogenéticas relacionadas à granitogênese do Cráton Amazônico. In: CONGRESSO BRASILEIRO DE GEOLOGIA, 33, Rio de Janeiro, 1984. Anais.... Rio de Janeiro, SBG. v.6, p.2963-2972.

TASSINARI, C.C.G.; HIRATA, W.K.; KAWASHITA, K. 1982. Geologic evolution of the Serra dos Carajás, Pará, Brazil. Rev. Bras. Geoc. 12: 263-267.

TAYLOR, P.N ; MOORBATH, S.; GOODWIN, R.; PETRYKOWSKI, A.C. 1980. Crustal contanination as an indicator of the extent of early Archean continental crust: $\mathrm{Pb}$ isotopic evidence from the late Archean gneisses of West Greenland. Geoch. Cosmoch. Acta 44:1437-1453.

WILLIAMSON, J.H. 1968. Least squares fitting of a straight line. Canadian Jounal of Physics, 56:1945-1947.

YORK, D. 1967. Least-squares fitting of a straight line. Canadian Journal of Physics, 44:1079-1086

YORK, D. 1969. Least-squares fitting of a straight lile with correlated erros. Earth Planet. Sci. Letters, 5:320-324.

Manuscrito A906

Recebido em 20 de janeiro de 1997

Revisão dos autores em 10 de julho de 1997 Revisão aceita em 15 de julho de 1997 